\title{
Perencanaan Enterprise Architecture di Rumah Sakit Umum Muhammadiyah Surya Melati Kediri
}

\author{
Intan Nur Farida*1, Abidarin Rosidi², Syamsul A. Syahdan ${ }^{3}$ \\ ${ }^{1}$ Mahasiswa Magister Teknik Informatika STMIK AMIKOM Yogyakarta \\ ${ }^{2,3}$ Dosen Magister Teknik Informatika STMIK AMIKOM Yogyakarta \\ E-mail: *1.in.nfarida@gmail.com,${ }^{2}$ abi@ amikom.ac.id, ${ }^{3}$ syamsul@ amikom.ac.id
}

\begin{abstract}
Abstrak
Pelayanan medis yang belum didukung oleh pemanfaatan teknologi secara optimal menimbulkan permasalahan terutama berkaitan dengan pelayanan medis pasien. Perencanaan arsitektur enterprise dalam mendukung aktivitas bisnis rumah sakit harus ada, meliputi arsitektur data, aplikasi dan teknologi. Tujuan perencanaan ini adalah membuat blueprint enterprise architecture di Rumah Sakit Umum Muhammadiyah Surya Melati Kediri sebagai pedoman pencapaian tujuan organisasi. Adapun konsep yang dipakai adalah EAP dengan menggunakan Zachman framework. Hasil dari perencanaan ini adalah terbentuknya entitas data, usulan aplikasi serta rencana peta jaringan sesuai dengan visi, misi dan tujuan organisasi sehingga tercipta pelayanan medis yang bermutu.
\end{abstract}

Kata Kunci - Enterprise architecture planning, Zachman framework, pelayanan medis

\begin{abstract}
Medical services are not supported by the use of technology in optimally cause problems mainly related to the patient's medical care. Enterprise architecture planning in support of the hospital business activity must exist, including data architecture, application and technology. The purpose of planning is to make enterprise architecture blueprint at Muhammadiyah Hospital Surya Melati Kediri to guide the achievement of organizational goals. The concept is used by EAP using the Zachman framework. Results of this project is the establishment of a data entity, applications and network plans in accordance with the vision, mission and goals of the organization so as to create the quality of medical care.
\end{abstract}

Keywords - Enterprise architecture planning, Zachman framework, medical service

\section{PENDAHULUAN}

Penggunaan teknologi untuk mendukung pelaksanaan kegiatan sehari-hari pada saat ini adalah adanya program billing system. Kendala yang dihadapi dalam menggunakan aplikasi tersebut antara lain: perangkat komputer belum ada di setiap ruangan dan pelayanan sehingga menyulitkan saat memasukkan data, jaringan kurang stabil, penyimpanan data pasien belum terpelihara secara menyeluruh serta belum ada ketenagaan yang memenuhi kualifikasi sebagai pemelihara data.

Permasalahan yang dihadapi menyangkut pengolahan data khususnya pada pelayanan rawat inap. Pelayanan administrasi pasien rawat inap yang akan meninggalkan rumah sakit membutuhkan waktu lama karena petugas RS harus mengumpulkan dokumen penanganan yang telah dilakukan sejak hari pertama dengan melapor kepada pegawai rekam medis. 
Berdasarkan latar belakang maka permasalahan yang akan diteliti dalam penelitian ini dirumuskan sebagai berikut: Bagaimana membuat blueprint perencanaan enterprisearchitecture di Rumah Sakit Umum Surya Melati Kediri sebagai pedoman untuk mendukung pencapaian tujuan organisasi.

Batasan variabel penelitian antara lain:Fokus pada perspektif planner dan owner sesuai dengan konsep EAP dalam mendefinisikan arsitektur-arsitektur dan mendefinisikan apa yang dibutuhkan serta merencanakan definisi arsitektur yang akan diimplementasikan. Mewujudkan perencanaan enterprise architecture dengan kerangka kerja Zachmanmeliputi aspek what, how dan where dari arsitektur sistem informasi sesuai dengan konsep EAP. Penelitian ini dilakukan pada bagian pelayanan medis di Rumah Sakit Umum Surya Melati Kediri.

Cetak Biru arsitektur enterprise merupakan rincian dinamis untuk arsitektur-arsitektur yang memanfaatkan proses dan kerangka yang terstruktur.[1] Penelitian ini bertujuan untuk merencanakan arsitektur enterprise dalam mendukung aktivitas bisnis rumah sakit menggunakan Zachman framework dengan membuat blueprint enterprisearchitecture di Rumah Sakit Umum Surya Melati Kediri sebagai pedoman pencapaian tujuan organisasi. Metode pendekatan EAP pada penelitian ini akan memudahkan pengolahan data, kinerja, membantu memberikan akses jaringan data dan meminimalisir kesalahan sehingga menghasilkan informasi yang baik dan tepat waktu.

Beberapa penelitian terdahulu, yaitu Analisis dan Desain Sistem Pelaporan Kerusakan Komputer Menggunakan konsep Zachman oleh Slameto tahun 2013, menitikberatkan pada sudut pandang Planner dan Owner dengan aspek kolom what, how, where, who, when, why namun belum menjelaskan entitas data secara detail.[2]

Penggunaan kerangka Zachman untuk membentuk latar belakang suatu pengambilan keputusan medis dilakukan oleh Dantu (2011) dengan variasi kolom dan baris matriks Zachman untuk sistem yang dinamis meskipun penjelasan variasi kolom matriks kurang jelas. [3] Penelitian yang dilakukan oleh Radwan (2011) menggunakan artifak Zachman framework untuk pemodelan pada perencanaan enterprise dalam sistem informasi di perusahaan. Penelitian ini menghasilkan dokumentasi terhadap seluruh artifak dari Zachman framework namun fokus pada pemodelan manufacturing enterprises aggregate planning. [4]

Perencanaan pembangunan sistem informasi terintegrasi dengan menerapkan metodologi EAP dan analisa dengan rantai nilai Porter oleh Eriya pada tahun 2011 menghasilkan pedoman dalam pembangunan sistem informasi terintegrasi dalam mengatasi masalah terpisahnya sistem informasi terhadap fungsi-fungsi bisnis.[5] Penelitian tentang perancangan rekomendasi solusi pengelolaan informasi di SBU Aircraft Services, PT. Dirgantara Indonesia oleh Falahah tahun 2010 mengungkapkan pengelolaan data skala enterprise sebagai kerangka bagi implementasi arsitektur namun belum menyajikan kolom dan baris matriks secara detil. [6]

Penelitian oleh Kurniawan pada tahun 2010 memodelkan arsitektur enterprise perguruan tinggi dengan Zachman Framework menggunakan analisa ValueChain dan CriticalSuccessFactor. Penelitian ini menghasilkan kerangka arsitektur enterprise berupa arsitektur data, aplikasi serta teknologi yang berorientasi pada kebutuhan bisnis.[7] Imbar pada tahun 2008 dengan framework yang sama telah memodelkan arsitektur enterprise di PT. Indonesia Power UBP Kamojang. Penelitian ini menggambarkan entitas bisnis dan data sesuai kebutuhan enterprise. [8]

\subsection{Enterprise Architecture}

Kata enterprisearchitecture terbentuk dari kata arsitektur dan enterprise. Arsitektur merupakan perancangan dari suatu benda atau merepresentasikan suatu gambaran yang sesuai dengan suatu obyek sehingga dapat diperoleh hasil yang sesuai dengan kebutuhan dan berkualitas. [9] Menurut Surendro (2007) arsitektur menyiratkan suatu perencanaan yang diwujudkan dengan model dan gambar dari komponen dari sesuatu dengan berbagai sudut pandang.[9] Untuk definisi enterprise mengandung arti keseluruhan komponen pada suatu organisasi dalam kepemilikan dan kontrol organisasi tunggal. [10] 
Sedangkan menurut CIO Council (2001) arsitektur enterprise adalah struktur dari komponen-komponen yang saling berhubungan satu dengan yang lainnya, serta terdapat prinsip dan aturan-aturan dalam merancang yang berkembang dari waktu ke waktu. [11]

Latar belakang dibentuknya konsep arsitektur enterprise adalah adanya kebutuhan organisasi dalam membangun sistem informasi untuk memisahkan data, proses, infrastruktur teknologi, orang, waktu, dan motivasi dalam suatu kerangka kerja arsitektur enterprise. [12]

\subsection{Zachman Framework}

Kerangka kerja (framework) dapat diartikan sebagai sejumlah pemikiran, konsep, ide atau asumsi yang digunakan untuk mengorganisasikan proses pemikiran tentang sesuatu atau situasi. Kerangka kerja ini juga dapat dianggap sebagai dasar berpikir untuk mengelompokkan dan mengorganisasikan representasi sebuah perusahaan yang penting bagi manajemen perusahaan dan pengembangan sistem selanjutnya. [9]

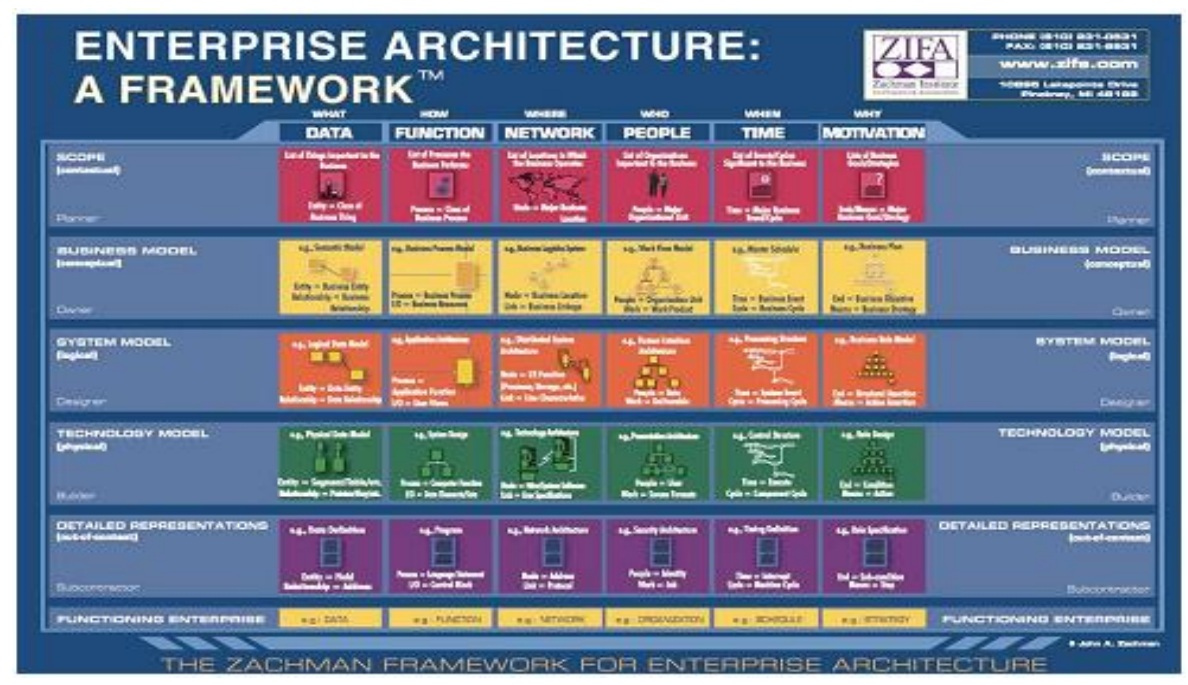

Gambar 1. Kerangka Kerja Zachman untuk EnterpriseArchitecture [9]

Kerangka kerja Zachman bukan suatu metodologi untuk mengembangkan enterprise architecture, akan tetapi kerangka kerja Zachman merupakan kerangka kerja untuk mengkategorikan artifak enterprisearchitecture. Kerangka kerja Zachman dapat dimanfaatkan untuk menentukan apakah suatu metodologi meliputi semua aspek dalam enterprisearchitecture atau aspek apa saja yang dicakup oleh metodologi. Kerangka kerja Zachman untuk enterprisearchitecture terdiri dari 6 (enam) kolom dan 6 (enam) baris, lihat Gambar 1.

\subsection{Enterprise Architecture Planning}

EnterpriseArchitecturePlanning (EAP) merupakan suatu pendekatan yang dibuat oleh Steven H. Spewak untuk membangun arsitektur enterprise dengan berdasarkan dorongan data dan dorongan bisnis. EnterpriseArchitecturePlanning adalah proses pendefinisian arsitektur dalam penggunaan informasi untuk mendukung bisnis dan rencana untuk mengimplementasikan arsitektur tersebut [13]

Hubungan antara kerangka kerja Zachman dan EAP adalah proses mendefinisikan dua level atas kerangka kerja Zachman. Jika dipetakan ke dalam kerangka kerja Zachman, EAP akan berada di baris pertama dan baris kedua yang merupakan perspektif perencana dan pemilik. Sedangkan aspek yang dibahas dalam EAP berada pada tiga kolom dari kerangka kerja Zachman, yaitu meliputi data, fungsi dan jaringan dari arsitektur sistem informasi. Cakupan EAP ke dalam kerangka kerja Zachman dinyatakan dalam Gambar 2. 


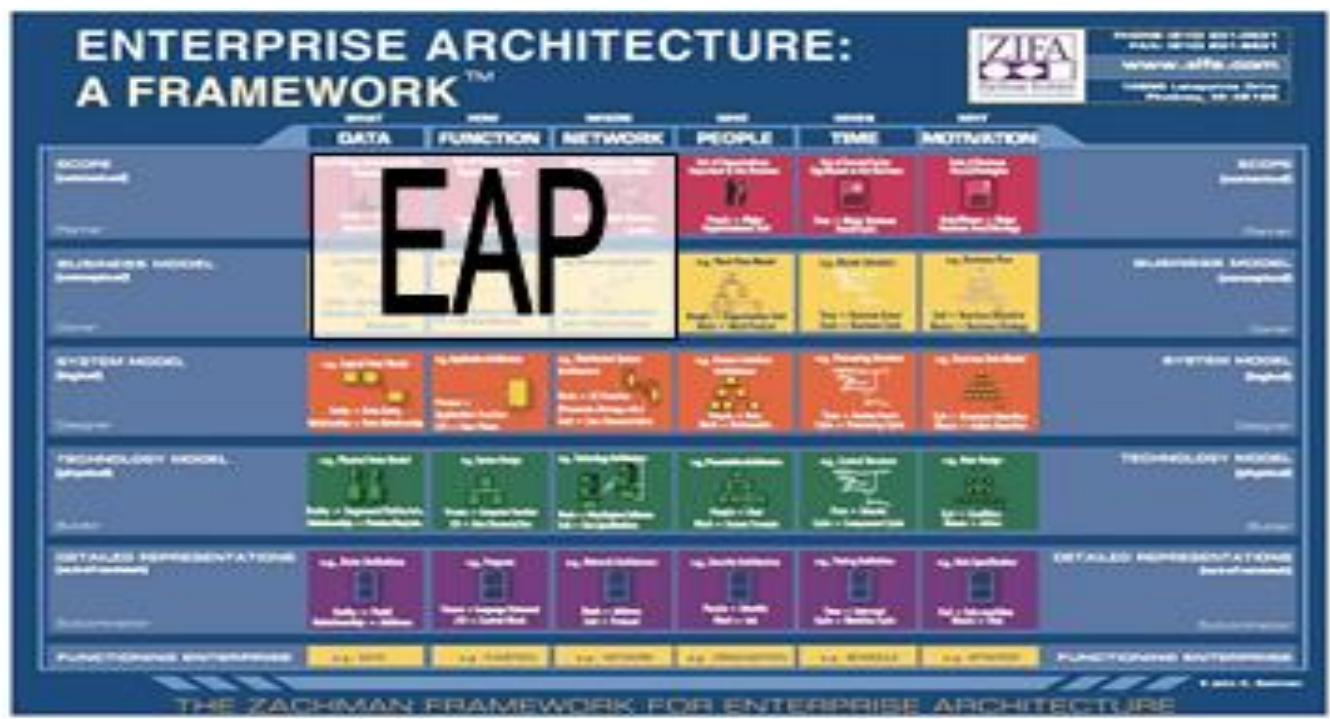

Gambar 2. Cakupan EAP dalam Kerangka Kerja Zachman [1]

Langkah-langkah dalam EAP memberikan panduan praktis dalam membuat arsitektur dari dua baris dan tiga kolom pertama kerangka kerja Zachman [1]

Perencanaan Arsitektur Enterprise merupakan kegiatan merencanakan, sehingga aktifitas yang dicakupnya yang terkait kerangka kerja Zachman adalah mendefinisikan data, aplikasi, dan teknologi dari dua perspektif utama yaitu perspektif perencana dan perspektif pemilik. Sedangkan empat perspektif Zachman berikutnya merupakan kegiatan perancangan, sehingga bukan termasuk komponen perencanaan. [1]

EnterpriseArchitecturePlanning memiliki tujuh komponen utama yang menunjukkan tahapan untuk menentukan dan merencanakan implementasi arsitektur sistem informasi. Tujuh komponen utama ini dikelompokkan menjadi empat lapisan. [13]

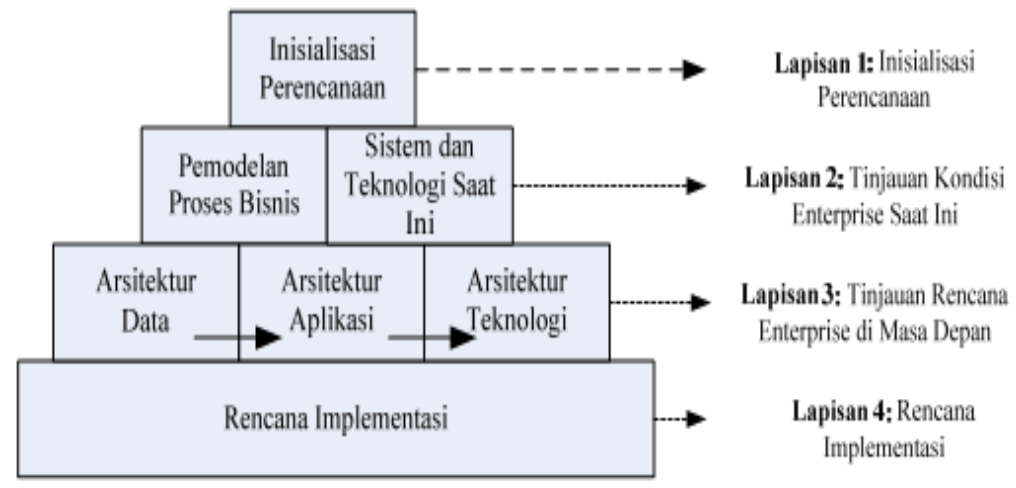

Gambar 3. Komponen dan Lapisan EnterpriseArchitecturePlanning[13] 
Citec Journal, Vol. 1, No. 1, November 2013 - Januari 2014

\section{METODE PENELITIAN}

\subsection{Metode Pengumpulan Data}

Pengumpulan data dilakukan dengan melakukan:

1. Observasi atau pengamatan langsung terhadap organisasi terkait dengan cara mempelajari dokumentasi, visi, tujuan, struktur organisasi, proses bisnis dan kebijakan teknologi informasi yang telah ada pada Rumah Sakit Umum Muhammadiyah Surya Melati Kediri.

2. Wawancara dengan pihak-pihak yang berkaitan dengan penelitian, mengenai kesulitankesulitan apa saja yang dihadapi oleh pihak Rumah Sakit serta aplikasi seperti apa yang diinginkan agar mengoptimalkan pelayanan kesehatan masyarakat.

\subsection{Metode Analisa Data}

Sistem analisa data yang dilakukan bertujuan untuk memperoleh gambaran logika tentang perencanaan enterprise architecture yang diinginkan secara detail sesuai metode yang digunakan. Tahap analisa dan rancangan disesuaikan dengan metodologi enterprise architecture planning (EAP) menggunakan Zachman framework.

Langkah-langkah penelitian dapat dilihat dalam bentuk diagram alir pada Gambar 4.

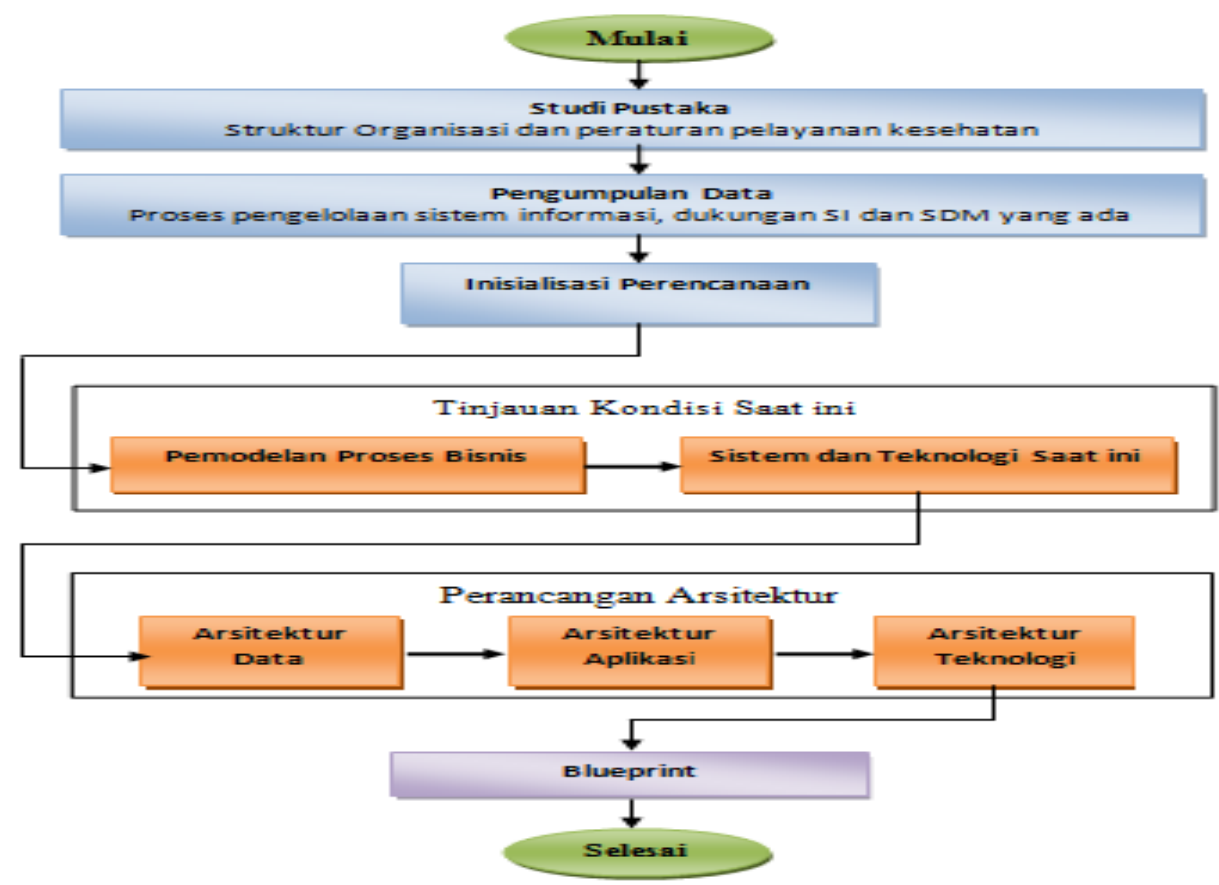

Gambar 4. Diagram Alir Penelitian

Perencanaan Arsitektur meliputi:

1. Arsitektur Data, kegiatan identifikasi dan pendefinisian entitas data yang diperlukan bagi perencanaan enterprisearchitecture guna mendukung fungsi bisnis.

2. Arsitektur Aplikasi, kegiatan identifikasi dan pendefinisian aplikasi-aplikasi yang dibutuhkan dalam pengelolaan data dan mendukung fungsi bisnis enterprise.

3. Arsitektur Teknologi, kegiatan ini meliputi identifikasi dan pendefinisian prinsip teknologi yang dibutuhkan dalam enterprise untuk mengelola data agar fungsi bisnis dapat berjalan baik. 


\section{HASIL DAN PEMBAHASAN}

\subsection{Inisialisasi Perencanaan}

Melakukan identifikasi atas aturan-aturan pelayanan medis untuk menentukan ruang lingkup. Berdasar-kan rencana strategis maka diketahui bahwa RSU Muhammadiyah Surya Melati Kediri memiliki:

Visi :Menjadi pusat layanan kesehatan bermutu dan Islami.

Misi :

1. Lengkapnya peralatan penunjang layanan

2. Sumber daya insani yang terampil dan kompeten

3. Pengelolaan keuangan yang akuntabel

4. Keterjangkauan pembiayaan

5. Dakwah Islamiyah melalui pelayanan kesehatan

Motto: Semangat Bisa, Ceria Berkarya.

Tujuan:

Membantu menciptakan tingkat kesehatan masyarakat yang optimal di semua lapisan dalam rangka mewujudkan masyarakat yang sejahtera, sehat dan makmur yang diridhoi Allah Subhanallahu Wa Ta'ala melalui pendekatan preventif, promotif, kuratif dan rehabilitatif secara menyeluruh.

\subsection{Tinjauan Kondisi Saat ini}

\subsubsection{Pemodelan Proses Bisnis}

Sesuai visi, misi dan tujuan organisasi maka dapat diketahui bahwa model bisnis di Rumah Sakit ini diwujudkan dalam bidang pelayanan kesehatan. Definisi proses bisnis dikaitkan dengan kegiatan pelayanan kesehatan yang telah dilakukan oleh Rumah Sakit Muhammadiyah Surya Melati. Pemodelan proses bisnis dilakukan dengan mengidentifikasi dan mendokumentasikan struktur organisasi, mengidentifikasi dan mendefinisikan fungsi bisnis. Dekomposisi fungsi bisnis digambarkan dengan penjelasan-penjelasan yang sesuai dengan fungsi yang dikerjakan.

Berdasarkan masing-masing proses akan diketahui pelaksanaan pada lokasi bisnis tiap unit organisasi. Hasil relasi antar fungsi bisnis yang telah didekomposisikan dengan unit organisasi dipetakan menggunakan matriks fungsi bisnis terhadap unit organisasi. Matriks relasi tersebut ditampilkan pada tabel 1. 
Citec Journal, Vol. 1, No. 1, November 2013 - Januari 2014

Tabel 1. Matriks Fungsi Bisnis terhadap Unit Organisasi

\begin{tabular}{|l|l|l|l|l|l|l|l|l|l|l|l|l|l|l|l|l|l|}
\hline Organisasi \\
$\begin{array}{l}\text { Fungsi } \\
\text { Bisnis }\end{array}$
\end{tabular}

\subsubsection{Kondisi Teknologi Saat ini}

Hasil pengamatan terhadap pelayanan medis ditemukan bahwa kondisi dukungan teknologi masih sangat kurang. Berdasarkan identifikasi pengamatan langsung terhadap kondisi sistem dan teknologi saat ini yang telah dijalankan pada pelayanan medis maka dapat diketahui:

1. Rumah sakit Umum Muhammadiyah Surya Melati menggunakan 1 komputer server dengan 9 unit komputer client dan terhubung dengan LocalAreaNetwork menggunakan kabel UTP dan tidak terhubung jaringan internet.

2. Pelaksanaan kegiatan sehari-hari menggunakan program BillingSystem sejak tahun 2005 menggunakan dasar program Microsoft Access dan dipadukan dengan database Microsoft SQL Server 2000.

3. Aplikasi keuangan menggunakan aplikasi General Ledger yang dimodifikasi dan dikembangkan dengan menggunakan Visual Foxpro.

4. BillingSystem belum terpasang di semua bagian fungsi bisnis Rumah Sakit, hanya di bagian pendaftaran, instalasi farmasi, laboratorium dan kasir.

5. Belum tersedia pengolahan data secara terintegrasi antar unit organisasi di Rumah Sakit Umum Muhammadiyah Surya Melati.

\subsection{Perencanaan Architecture Enterprise}

\subsubsection{Arsitektur Data}

Pendefinisian dan identifikasi dalam arsitektur data dilakukan dengan membuat daftar entitas data. Yaitu melakukan identifikasi entitas bisnis dengan menganalisa fungsi utama bisnis pelayanan medis yang telah diuraikan pada tahap pemodelan bisnis. Entitas data yang diidentifikasi menunjukkan fungsi atau entitas bisnis. Dari masing-masing entitas bisnis akan ditentukan entitas data yang mewakili aktivitas dari tiap entitas bisnis.

Matriks hubungan entitas bisnis menunjukkan entitas data yang digunakan dalam perencanaan enterprisearchitecture. Masing-masing sel dalam matriks diisi dengan huruf $\mathrm{C}$ (create), $\mathrm{U}$ (update) dan $\mathrm{R}$ (reference). Penanda tersebut bermakna proses yang bersangkutan membuat (create), melakukan update danmenggunakan (reference) entitas data terjkait. Proses yang melakukan $\mathrm{C}$ mengimplikasikan $\mathrm{U}$ dan $\mathrm{R}$, sedangkan proses yang melakukan $\mathrm{U}$ mengimplikasikan R.[1] Ditunjukkan pada tabel 2. 
Tabel 2. Matriks Entitas Bisnis dengan Entitas Data

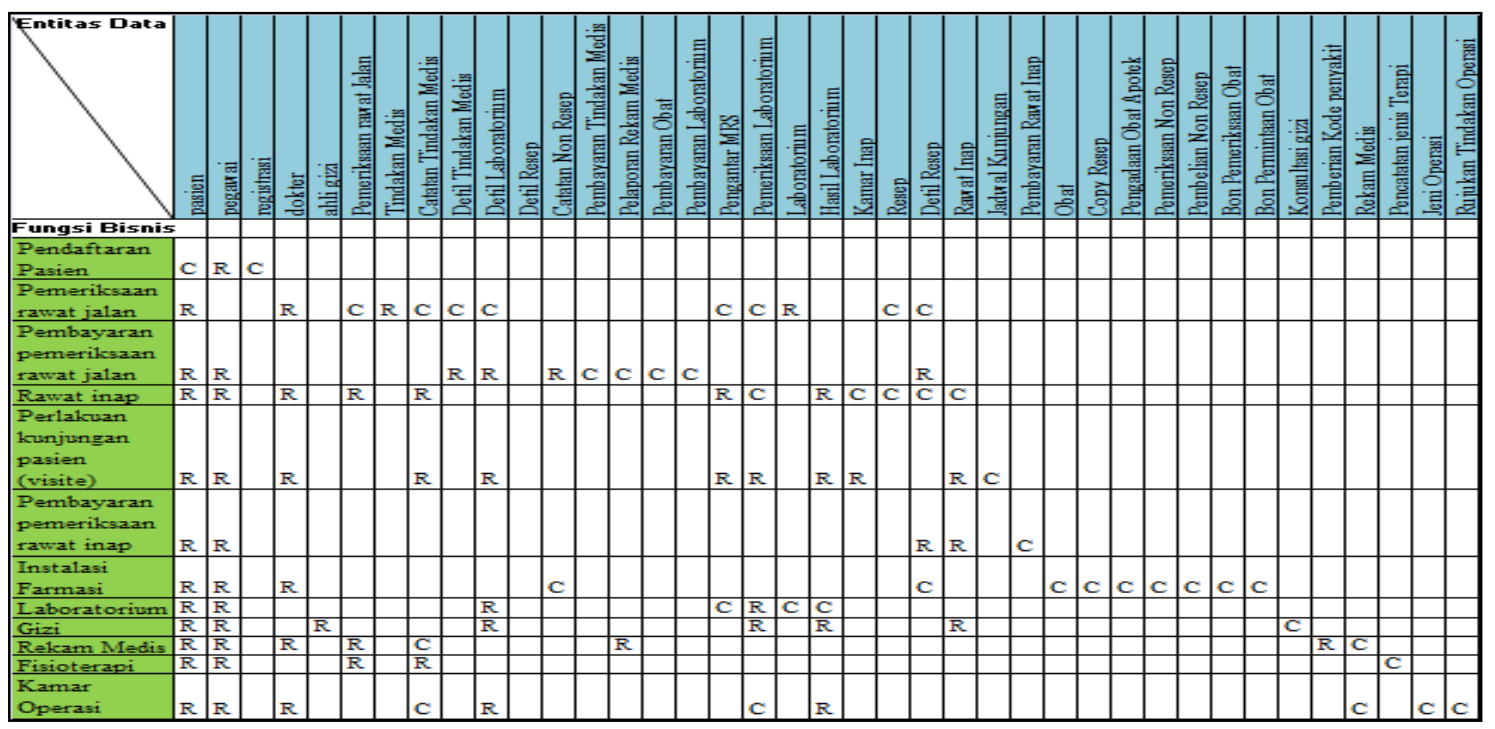

\subsubsection{Arsitektur Aplikasi}

Tabel 3. Kandidat Aplikasi dan Deskripsi

\begin{tabular}{|l|l|l|}
\hline No. & \multicolumn{1}{|c|}{$\begin{array}{c}\text { Kandidat } \\
\text { Aplikasi }\end{array}$} & \multicolumn{1}{|c|}{ Deskripsi } \\
\hline 1. & Registrasi Pasien & $\begin{array}{l}\text { Aplikasi yang digunakan untuk mengolah } \\
\text { pendaftaran pasien }\end{array}$ \\
\hline 2. & $\begin{array}{l}\text { Sistem Rawat } \\
\text { Jalan }\end{array}$ & $\begin{array}{l}\text { Aplikasi yang digunakan untuk memudahkan } \\
\text { pelayanan pemerik-saan pasien yang dirawat di } \\
\text { poliklinik }\end{array}$ \\
\hline 3. & $\begin{array}{l}\text { Sistem Rawat } \\
\text { Inap }\end{array}$ & $\begin{array}{l}\text { Aplikasi yang digunakan untuk memudahkan } \\
\text { pelayanan pasien dalam perawatan inap rumah sakit }\end{array}$ \\
\hline 4. & $\begin{array}{l}\text { Sistem Instalasi } \\
\text { Farmasi }\end{array}$ & $\begin{array}{l}\text { Aplikasi yang digunakan untuk memudahkan } \\
\text { pengolahan data obat-obatan baik dengan resep } \\
\text { maupun non resep }\end{array}$ \\
\hline 5. & $\begin{array}{l}\text { Sistem Rekam } \\
\text { Medis }\end{array}$ & $\begin{array}{l}\text { Aplikasi yang digunakan untuk memudahkan } \\
\text { pengolahan tindakan dan catatan medis pasien }\end{array}$ \\
\hline 6. & $\begin{array}{l}\text { Sistem } \\
\text { Laboratorium }\end{array}$ & $\begin{array}{l}\text { Aplikasi yang digunakan untuk memudahkan } \\
\text { pengolahan data pemeriksaan dalam labotarorium }\end{array}$ \\
\hline 7. & Sistem Gizi & $\begin{array}{l}\text { Aplikasi yang membantu memberikan informasi dan } \\
\text { pemahaman tentang kebutuhan gizi bagi pasien }\end{array}$ \\
\hline 8. & Kasir & $\begin{array}{l}\text { Aplikasi yang digunakna untuk membantu } \\
\text { pengolahan data pembayaran selama proses } \\
\text { pelayanan medis }\end{array}$ \\
\hline
\end{tabular}

Pendefinisian aplikasi ditujukan untuk mendefinisikan aplikasi yang diperlukan untuk mengelola entitas data yang telah diidentifikasi untuk mendukung fungsi bisnis. Perencanaan enterprise architecture menunjukkan bahwa identifikasi arsitektur aplikasi bertujuan untuk menyediakan informasi dalam menyelenggarakan fungi bisnis.

Untuk mendefinisikan kandidat aplikasi maka dilakukan dengan melakukan analisis hubungan antara fungsi bisnis dan entitas data yang telah dihasilkan. Dari analisis tersebut 
Citec Journal, Vol. 1, No. 1, November 2013 - Januari 2014

ISSN: 2354-5771

kemudian dikelompokkan sehingga mendapatkan kandidat aplikasi. Kandidat aplikasi ditunjukkan oleh tabel 3.

Hubungan antara unit organisasi terhadap aplikasi ditujukan untuk menunjukkan dukungan unit organisasi di Rumah Sakit Umum Muhammadiyah Surya Melati yang akan diusulkan. Hubungan antara unit organisasi RS terhadap aplikasi disajikan pada tabel 4.

Tabel 4. Matriks Hubungan Unit Organisasi terhadap Aplikasi

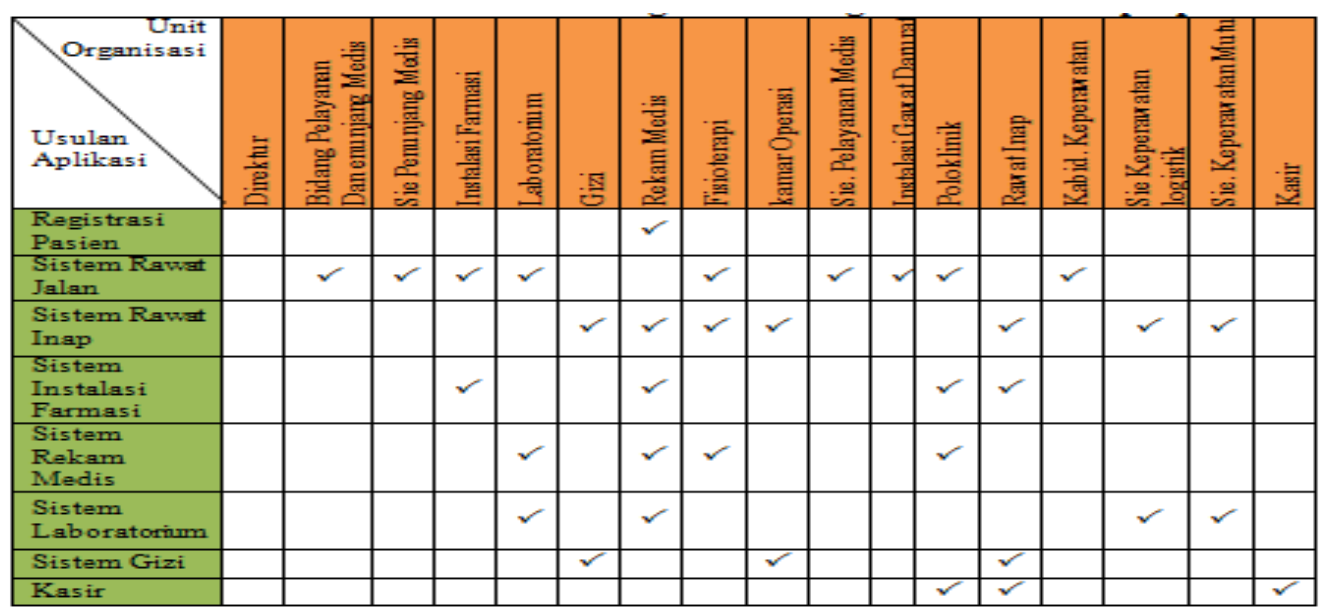

\subsubsection{Arsitektur Teknologi}

Pendefinisian dan identifikasi arsitektur teknologi bertujuan untuk mendefinisikan jenis teknologi yang akan digunakan dalam mengoperasikan aplikasi dan pengelolaan data yang diidentifikasi.

Pemilihan teknologi yang akan digunakan dalam lingkungan aplikasi guna mendukung pelayanan medis di Rumah Sakit Umum Muhammadiyah Surya Melati Kediri. Pemilihan platform teknologi ditunjukkan pada tabel 5 .

Tabel 5. Prinsip Platform Teknologi

\begin{tabular}{|ll|l|l|}
\hline \multicolumn{1}{|c|}{ Hardware } & \multicolumn{1}{|c|}{ Software } & \multicolumn{1}{c|}{ Communication } \\
\hline $\begin{array}{l}\text { Komputer: PC yang } \\
\text { kompatibel, Server }\end{array}$ & Sistem Operasi: Windows & $\begin{array}{l}\text { Jaringan: } \\
\text { LAN/ WAN, Internet }\end{array}$ \\
\hline $\begin{array}{l}\text { 2. } \\
\text { Piranti Masukan: Mouse, } \\
\text { keyboard }\end{array}$ & Spreadsheet: MicrosoftExcel & Telepon \\
\hline $\begin{array}{l}\text { 3. } \\
\text { Piranti Keluaran: } \\
\text { Monitor, Printer }\end{array}$ & $\begin{array}{l}\text { Pengolah Kata: } \\
\text { MicrosoftWord }\end{array}$ & \\
\hline & $\begin{array}{l}\text { Sistem Basis Data: } \\
\text { SQL Server }\end{array}$ & \\
\hline & $\begin{array}{l}\text { Pembangun-an Aplikasi: } \\
\text { Java, Aplikasi potable/ PHP }\end{array}$ \\
\hline & $\begin{array}{l}\text { Aplikasi Internet: Software } \\
\text { browser, Messenger }\end{array}$ & \\
\hline
\end{tabular}

Berdasarkan identifikasi platform teknologi yang dihubungkan dengan aplikasi dan fungsi maka desain jaringan yang akan dibangun dalam mendukung proses bisnis pelayanan medis di Rumah Sakit Umum Muhammadiyah Surya Melati Kediri ditunjukkan dalam gambar 5. 


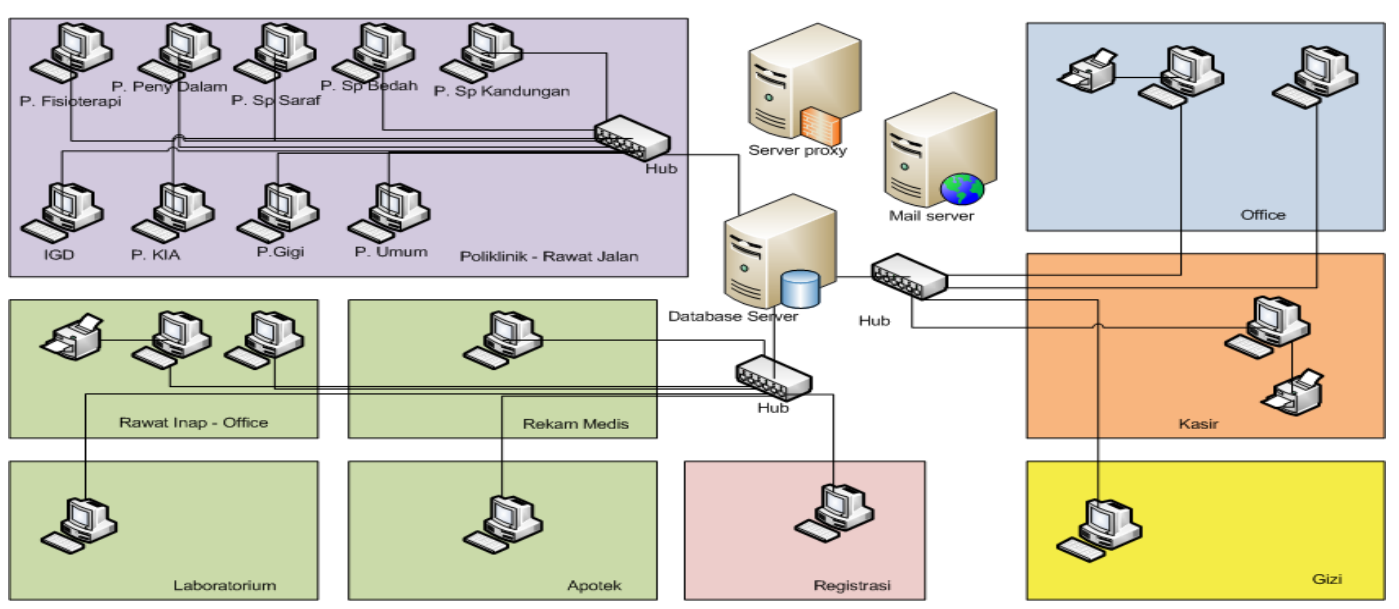

Gambar 5. Peta Jaringan di Rumah Sakit Umum Surya Melati Kediri

\section{KESIMPULAN}

Berdasarkan pembahasan yang telah diuraikan maka terdapat kesimpulan sebagai berikut:

1. Perencanaan Arsitektur enterprise dalam mendukung pelayanan medis rumah sakit Umum Muhammadiyah Surya Melati Kediri menghasilkan identifikasi arsitektur data sebanyak 39 entitas, arsitektur aplikasi terdiri dari 9 aplikasi dan arsitektur teknologi dengan menambah 4 node jaringan.

2. Pemodelan menggunakan pendekatan EAP meliputi seluruh bagian pelayanan medis yang disesuaikan dengan kondisi yang ingin dicapai di Rumah Sakit Umum Surya Melati Kediri.

\section{SARAN}

Adapun saran untuk pengembangan perencanaan enterprise architecture selanjutnya antara lain:

1. Penggunaan kolom matriks Zachman framework secara lebih detil untuk merencanakan arsitektur enterprise Rumah Sakit.

2. Pengembangan dapat dilakukan untuk bagian non medis Rumah Sakit.

3. Perencanaan dengan menggunakan tool yang sesuai untuk memudahkan identifikasi dan definisi arsitektur data, aplikasi dan teknologi.

\section{DAFTAR PUSTAKA}

[1] Surendro, K, 2009, Pengembangan Rencana Induk Sistem Informasi, Informatika Bandung, Bandung.

[2] Slameto, A. A., Utami, E., Pangera, A. A., 2013, Penerapan Zachman Framework dalam Merancang Sistem Pelaporan Kerusakan Komputer, Semnasteknomedia 2013, 13 Januari 2013.

[3] Dantu, B., Smith, E., 2011, Medical Process Modeling with a Hybrid System Dynamics Zachman Framework, Procedia Computer Science, Vol 6, hal 76-81.

[4] Radwan, A., Aarabi, M., 2011, Study of Implementing Zachman Framework for Modeling Information Systems for Manufacturing Enterprises Aggregate Planning, Proceedings of the 2011 International Conference on Industrial Engineering and Operations Management, Kuala Lumpur, Malaysia, January 2011. 
Citec Journal, Vol. 1, No. 1, November 2013 - Januari 2014

[5] Eriya, Surendro, K., 2011, Perencanaan Pembangunan Sistem Informasi Terintegrasi dengan Enterprise Architecture Planning (EAP) (Studi Kasus: STIKOM Dinamika Bangsa Jambi), Konferensi Nasional Sistem Informasi 2011, Medan, 25-26 Februari 2011.

[6] Falahah, Rosmala, D., 2010, Penerapan Framework Zachman pada Arsitektur Pengelolaan Data Operasional (Studi Kasus SBU Aircraft Services, PT. Dirgantara Indonesia), Seminar Nasional Aplikasi Teknologi Informasi 2010 (SNATI 2010), Yogyakarta, Juni 2010.

[7] Kurniawan, B., 2010, Enterprise Architecture Planning Sistem Informasi pada Perguruan Tinggi Swasta dengan Zachman Framework, Majalah Ilmiah UNIKOM, Vol. 9, No. 1.

[8] Imbar, R. V., Agustin, R., 2008, Analisis dan Pemodelan Enterprise Architecture PT. Indonesia Power UBP Kamojang Menggunakan Metode Zachman Framework, Jurnal Sistem Informasi, Vol. 3, No. 1, hal $1-19$.

[9] Zachman, JA, 1997, Enterprise Architecture: The Issue of The Century, Database Programming and Design, Zachman International, Inc., Kanada.

[10] Lankhorst et al, 2005, Enterprise Architecture at Work: Modelling, Communication, and Analysis, Springer, Berlin.

[11] [CIO Council] Chief Information Officer Council. 2001, A Practical Guide to Federal Enterprise Architecture, Version 1.0., Springfield, Boston.

[12] Zachman, JA, 2003, Zachman Framework for Enterprise Architecture, Primer for Enterprise Engineering and Manufacturing, Ed ke-1b, OMG BRWG RFI: Zachman International, in press.

[13] Spewak, S. H., Hill, S.C., 1992, Enterprise Architecture Planning, John Wiley \& Sons, Inc.

[14] Sangadji, E. M., Sopiah, 2010, Metodologi Penelitian-Pendekatan Praktis dalam Penelitian, Andi, Yogyakarta. 